\title{
AS METODOLOGIAS DE REMUNERAÇÃO VARIÁVEL ADOTADAS PELAS EMPRESAS BRASILEIRAS E SUA INFLUÊNCIA NA MUDANÇA ORGANIZACIONAL
}

\author{
VILAS BOAS, ANA ALICE \\ Universidade Federal Rural do Rio de Janeiro \\ Doutora Administração \\ analice@ufrrj.br \\ BATISTA, LUCIENE GOUVEIA \\ Centro Universitário Associação Brasileira de Ensino Universitário \\ Mestre em Administração \\ lucienegouveia@ig.com.br
}

\begin{abstract}
RESUMO
Este trabalho foi realizado partindo do pressuposto que os salários e benefícios praticados nas organizações podem influenciar significativamente o desempenho e/ou os resultados empresariais até então apresentados pelas empresas; o que é de extrema importância para empresas que vivenciam um momento de mudança organizacional. Neste contexto, esta pesquisa teve como objetivo principal revisar as metodologias de remuneração de pessoal e, realizar uma análise comparativa das práticas adotadas pelas empresas no Brasil e da sua influência na mudança organizacional. Esta pesquisa teórica e prática foi implementada através da revisão bibliográfica e da pesquisa de campo. Devido ao nível de complexidade do tema em questão foi utilizada a pesquisa exploratória, para melhor verificar como a remuneração influencia no processo de mudança organizacional. Com base em quatro estudos de caso que foram desenvolvidos a partir de uma análise de conteúdo documental e da análise de questionários, observou-se que a remuneração variável é bastante utilizada como complemento do salário base. O resultado deste trabalho leva-nos a conclusão de que as metodologias de remuneração praticadas pelas empresas analisadas neste estudo foram capazes de influenciar positivamente seus resultados, auxiliando a implementação da mudança organizacional.
\end{abstract}

Palavras chave: Salário, motivação, resultados, estratégia.

Abstract: The aim of this paper is to look into the remuneration methodologies for the working people and, to perform a comparative analysis of the practices adopted by companies in Brazil and their interaction with the organizational change. The exploratory research was adopted to verify how the payment system affects the process of organizational change. Based on four case studies that were developed starting from an analysis of document's content, it was observed that flexible payment system have been adopted as complementary to the basic wage. This practice is well accepted by the employees and has motivated them in their jobs. The result of this work drives to the conclusion that remuneration methodologies practiced by the companies analyzed in this study positively influenced their results, assisting the implementation of the organizational change. 


\section{Revista Eletrônica de Ciência Administrativa (RECADM) - ISSN 1677-7387 \\ Faculdade Cenecista de Campo Largo - Coordenação do Curso de Administração v. 3, n. 1, maio/2004 - http://revistas.facecla.com.br/index.php/recadm/}

Key-words: Wage, Organizational Environment, Human Resources Management

Área Temática: Gestão de recursos humanos, segurança e qualidade de vida no trabalho

\section{Introdução}

A administração salarial tem sido fonte de estudo dos Departamentos de Recursos Humanos das empresas devido à sua relação com o comportamento apresentado por seus funcionários. Como decorrência destes estudos, novas metodologias de remuneração de pessoal surgiram dentro do cenário da Administração de Recursos Humanos. Porém, o processo de adesão das novas metodologias por parte das empresas, continua sendo lento. O modelo de remuneração funcional, baseado no cargo ou função, continua sendo o mais tradicionalmente usado nas empresas (Chiavenato, 1999 e Nascimento, 2001). No Brasil, as empresas que adotam estas novas metodologias, são em sua grande maioria empresas multinacionais, ou de tecnologia de ponta, que precisam de agilidade e flexibilidade e estão em constante processo de inovação (Wood Jr. \& Picarelli Filho, 1999).

A implantação de uma mudança organizacional pode representar um momento crítico para as empresas que precisam de um ambiente interno que favoreça seu pleno crescimento. Partindo deste pressuposto, este paper busca analisar a influência existente entre a metodologia de remuneração adota pelas empresas no Brasil e a implementação da mudança organizacional.

O problema principal a ser considerado é verificar se as metodologias de remuneração adotadas pelas empresas são capazes de influenciar positiva ou negativamente os resultados num dado ambiente de mudanças organizacionais.

\section{Referencial Teórico}

\subsection{Administração de Salários e Remuneração Tradicional}

A administração de salários, para Chiavenato (1999), é o conjunto de normas e procedimentos utilizados para estabelecer e/ou manter estruturas de salários eqüitativas e justas na organização. A função da sua existência nas organizações é a de implantar um sistema de remuneração que mantenha adequada a relação vertical entre salários, ajustando esse sistema ou plano à realidade de mercado e estabelecendo um correto regime de estímulos ao aumento da eficiência e produtividade do trabalhador.

A pesquisa salarial é um instrumento de apoio da administração de salários, que monitora os salários praticados para os cargos no mercado, baseando-se em amostras de cargos que representam os demais cargos da organização e em amostras de empresas que representam o mercado de trabalho. A pesquisa salarial tem por objetivo informar qual a situação do mercado concorrente e comparar com os dados da empresa pesquisadora. Assim, a pesquisa salarial constitui-se num importante investimento para a manutenção de um plano de cargos e salários adequados.

Este mesmo autor afirma que a política salarial representa o conjunto de decisões organizacionais tomadas a respeito de assuntos relacionados com a remuneração e benefícios concedidos aos funcionários e reúne as diretrizes da empresa para a administração de salários.

A estrutura de cargos e salários predominantemente adotada pelas empresas, já perdura muito tempo, com raras e poucas alterações e inovações substanciais. Constitui-se basicamente de uma classificação hierarquizada de cargos, resultante de processos de 


\section{Revista Eletrônica de Ciência Administrativa (RECADM) - ISSN 1677-7387 \\ Faculdade Cenecista de Campo Largo - Coordenação do Curso de Administração v. 3, n. 1, maio/2004 - http://revistas.facecla.com.br/index.php/recadm/}

descrição e avaliação dos mesmos, associada com uma estrutura hierarquizada de salários, cujos pontos de referência são obtidos através de pesquisa de mercado.

A remuneração tradicional também conhecida por remuneração funcional, ou remuneração por cargo, é a forma mais tradicional utilizada pelas empresas para recompensar seus funcionários por seu trabalho, representando ainda hoje a "âncora” ou seja, a maior parcela do "mix" total de remuneração. Todavia, as empresas continuam usando a remuneração funcional pelos seguintes fatores:

- É implantada junto com o sistema de cargos e salários, o que ajuda a dar coerência interna à organização, proporcionando definições básicas que ajudam a estruturar o trabalho;

- Permite a eqüidade externa. Por meio de pesquisas salariais a empresa pode comparar seus salários com os praticados no mercado e, assim, estabelecer diretrizes adequadas para atrair e reter a mão-de-obra desejada; e

- Permite a eqüidade interna. Ter os salários estabelecidos a partir de regras aplicáveis a todos da empresa, o que produz um sentimento de justiça entre os funcionários.

A remuneração funcional, em sua forma tradicional, representa uma forma de pensar a gestão de recursos humanos nas empresas. Essa maneira é adequada para determinados tipos de negócios, para certo contexto estratégico e para alguns modelos de estrutura organizacional. Contudo, no mundo em mudança acelerada, talvez seja um risco alto demais manter um sistema desse tipo, que apresenta uma série de contradições com as práticas gerenciais emergentes. Porém, ela deve continuar sendo utilizada por muito tempo. Muitas empresas continuarão empregando o sistema para atingir um patamar de estruturação mais adequado. Porém, é imperativo que as inovações sejam realizadas para adequar seus diversos componentes à nova realidade.

Os principais métodos de remuneração funcional ou por cargo, citados por Chiavenato (1999) são: o método de escalonamento simples, o método de categorias predeterminadas, o método de comparação por fatores e o método de avaliação por pontos, esse último tornou-se o método de avaliação e remuneração dos cargos mais conhecido e utilizado do mundo. De acordo com Wood Jr. \& Picarelli Filho (1999), as principais críticas e limitações da remuneração tradicional são: promove um estilo burocrático de gestão; reduz a amplitude de ação dos indivíduos e grupos; inibe a criatividade e o espírito empreendedor; não considera o foco nos clientes internos e externos; reforça a orientação do trabalho para o supervisor hierárquico; promove a obediência a normas e procedimentos; não tem orientação estratégica ou para resultados; não encoraja o desenvolvimento de habilidades e conhecimentos; torna as promoções excessivamente importantes e incentiva o carreirismo.

A remuneração funcional foi desenvolvida para a empresa burocrática organizada segundo os princípios da divisão rígida de funções e tarefas, das linhas de autoridade e responsabilidades bem definidas e foco no controle. Esses princípios estão desaparecendo nas empresas modernas. Modelos flexíveis, focados no trabalho em grupo e no compartilhamento de responsabilidades, estão sendo maciçamente adotados pelas organizações (Wood Jr \& Picarellli Filho, 1999).

\subsection{Remuneração Variável}

A remuneração variável é uma forma complementar de remuneração baseada no desempenho que vem sendo adotada por um número maior de empresas nos últimos anos, principalmente para os cargos de diretoria e gerência. A tendência da remuneração é a quebra de um paradigma ainda hoje existente. Ela deixará de ser vista como uma provisão 


\section{Revista Eletrônica de Ciência Administrativa (RECADM) - ISSN 1677-7387 \\ Faculdade Cenecista de Campo Largo - Coordenação do Curso de Administração v. 3, n. 1, maio/2004 - http://revistas.facecla.com.br/index.php/recadm/}

normal, uma despesa necessária e passará a ter o intuito de promover um retorno, tornandose um investimento estratégico.

Em meio a um ambiente de turbulência econômica, as empresas têm valorizado mais a remuneração variável, a retenção de talentos, o atingimento dos seus objetivos estratégicos e o desenvolvimento de competências. Elas estão deixando de lado a remuneração fixa, benefícios indiretos e comparação simples com o mercado. Com isso, diante deste cenário, sobrevivem somente as empresas mais ágeis e produtivas, enquanto que do lado dos colaboradores, nada é diferente: permanecem aqueles que apresentarem melhores resultados, possibilitando, inclusive, serem reconhecidos e melhor remunerados.

Para Chiavenato (1999), a remuneração variável é um tema cada vez mais discutido em tempos de globalização. A competitividade crescente vem obrigando as empresas a descobrir novas estratégias para manter seus funcionários motivados e produtivos, obtendo, desta forma, resultados positivos para o negócio.

Wood Jr \& Picarellli Filho (1999) afirma que no Brasil, os modelos mais conhecidos de remuneração variável são bônus, comissão, campanhas de incentivo, participação nos lucros e nos resultados, remuneração por competências, por habilidades e remuneração estratégica. A remuneração variável deve ser encarada como uma oportunidade de modernizar a relação capital x trabalho, garantindo a competitividade da empresa, já que atualmente, o grande diferencial de mercado será o capital humano.

A empresa que decide implementar um plano de remuneração variável precisa ter em mente que ele é um fator de vantagem competitiva, que irá alavancar os resultados estratégicos. Existem alguns fatores críticos para o sucesso de um sistema de remuneração: a importância de uma orientação estratégica clara, garantia de que os objetivos estejam ao alcance dos grupos e indivíduos, existência de um horizonte pré-determinado e alto grau de flexibilidade (Wood Jr \& Picarellli Filho, 1999).

Para Chiavenato (1999), os benefícios das formas de remuneração variável respondem por parte considerável da remuneração total e costumam ser fator de decisão na aceitação de ofertas de emprego. A importância dos benefícios também advém do impacto sobre a imagem da empresa na comunidade. O oferecimento de benefícios é essencial para a atração e retenção da mão-de-obra, especialmente quando os requisitos do negócio impõem alto nível de capacitação profissional. Os benefícios, diante dessa nova consciência, ganham outra configuração, pois precisam responder aos motivos que impulsionam as pessoas a se sentirem satisfeitas. Hoje, os benefícios não podem mais ser vistos apenas como elementos compensatórios, mas se tornarem, na prática, fatores de alavancagem de qualidade de vida e da produtividade.

Algumas empresas estão respondendo às mudanças ocorridas no ambiente através da flexibilização nos planos de benefícios (Wood Jr \& Picarelli Filho, 1999). Os planos fixos pressupõem, por parte da empresa, uma postura paternalista e de controle e os flexíveis, ao contrário, pressupõem maturidade por parte da empresa, dos funcionários e da própria relação entre as partes. Os planos flexíveis dão aos funcionários a opção de escolher, entre os benefícios disponíveis, aqueles que são mais adequados ao seu perfil, condição familiar e estilos de vida. Um plano flexível, além de possibilitar maior ajuste entre o valor investido pela empresa e o valor percebido pelo funcionário, é também fator de reforço de traços culturais e apoiador de um estilo gerencial mais aberto e moderno.

A flexibilização dos planos de benefícios é coerente com o conceito de remuneração estratégica e com todas as tendências mais recentes de modernização da gestão de recursos humanos. Os benefícios também podem ser uma fonte de vantagem competitiva, ajudando a empresa a atrair e reter os profissionais que deseja.

Para Picarelli Filho \& Equipe Coopers \& Lybrand (1997), a remuneração estratégica trata dos vários aspectos do modelo de remuneração variável, enfatizando sua 


\section{Revista Eletrônica de Ciência Administrativa (RECADM) - ISSN 1677-7387 \\ Faculdade Cenecista de Campo Largo - Coordenação do Curso de Administração v. 3, n. 1, maio/2004 - http://revistas.facecla.com.br/index.php/recadm/}

aderência e convergência com as estratégias da empresa. A remuneração estratégica é também um catalisador para convergência de energias na organização. À medida que o sistema de remuneração é alinhado ao contexto e a estratégia da empresa, ele passa a constituir fator de harmonização de interesses, ajuda a gerar consensos e atua como alavanca de resultados.

O sistema de remuneração estratégica é uma combinação equilibrada de diferentes formas de remuneração. A remuneração funcional e a remuneração por habilidades ou por competências constituem a base de um sistema de remuneração. O salário indireto completa, com essas duas, a parte fixa da remuneração. A remuneração variável e a participação acionária compõem os itens referentes à remuneração por desempenho. Finalmente, as alternativas criativas completam o quadro, dando enfoque às formas especiais de remuneração.

Em suma, existem várias alternativas de remuneração variável, mas o objetivo é sempre o mesmo: garantir a convergência de esforços para melhorar o desempenho da empresa (Wood Jr \& Picarellli Filho, 1999).

\subsection{Remuneração e Mudança Organizacional}

Entender o contexto do processo de mudanças na era da globalização é fundamental para compreender a emergência dos novos sistemas de remuneração. Para Picarelli Filho \& Equipe Coopers \& Lybrand (1997), a mudança organizacional refere-se a qualquer transformação de natureza estratégica, estrutural, cultural, tecnológica, humana, ou de qualquer outro fator capaz de gerar impacto em partes ou no conjunto da organização.

A competitividade constituiu o foco das preocupações empresariais neste início de século. A fim de enfrentarem um ambiente crescentemente competitivo, as organizações sentem-se pressionadas a promoverem mudanças estratégicas em ritmo cada vez mais acelerado. Neste contexto, o processo de mudança organizacional configura-se não como fenômeno excepcional, mas como rotina, muitas vezes de difícil assimilação, no universo organizacional.

O pressuposto adotado em grande parte dos processos de mudança organizacional é o de que a transformação organizacional pode ser administrada, isto é, conduzida segundo as intenções e expectativas dos líderes formais.

A mudança organizacional deve ser entendida além dos chamados processos planejados de mudança. É necessário reconhecer três tipos de forças que podem provocar mudança: a relação entre as organizações e seu ambiente; o crescimento por meio dos estágios do ciclo de vida; e o exercício da política, ou seja, a constante luta pelo poder. Todos eles podem ocorrer à margem das intenções estratégicas e objetivos oficiais, obrigando a organização a se manter em contínuo movimento.

No estabelecimento de estratégias de mudança organizacional planejada interferem, ainda, fatores de natureza cognitiva através da percepção do que se entende como ambiente de competição acirrada ou concorrência e, em sentido mais amplo, o próprio modo de interpretar a realidade, delimitado por valores e crenças compartilhados na organização, que influenciam tanto na constatação da necessidade de mudança como no modo de conduzi-la.

A mudança organizacional se processa à medida que novos valores e regras se incorporam ao contexto institucional de referência. As regras e significados compartilhados no interior do contexto institucional da organização podem servir como buffers (ou amortecedores) que dificultam a assimilação de práticas emergentes em um contexto mais amplo, caso tais práticas não se coadunem com os valores vigentes. 


\section{Revista Eletrônica de Ciência Administrativa (RECADM) - ISSN 1677-7387 \\ Faculdade Cenecista de Campo Largo - Coordenação do Curso de Administração v. 3, n. 1, maio/2004 - http://revistas.facecla.com.br/index.php/recadm/}

Como poderosa fonte de motivação, a remuneração pode ser muito eficaz para angariar "corpo e alma” dos funcionários durante as fases de mudança em massa (Flannery, 1997). Se usada eficientemente, pode apressar a aceitação e o compromisso com a mudança. A remuneração é uma ferramenta importante para a comunicação e para reforçar novos valores e comportamentos, dando suporte para a responsabilidade por resultados e recompensando o alcance de novas metas de desempenho. Em suma, ela é o passo crucial para as pessoas se engajarem nos processos de mudança. Porém, o pagamento de salários em si não pode dirigir ou conduzir o processo de mudança organizacional, nem definir quais serão as mudanças que deverão ocorrer. Ele não pode estabelecer valores e não pode substituir a liderança eficaz no caminho do sucesso.

A remuneração deve ser considerada no amplo contexto das iniciativas de mudança e utilizada para dar suporte, tornando-se um ponto essencial para aqueles que estiverem envolvidos no desenvolvimento de estratégias e de pagamento de pessoal. Deve-se também compreender como o trabalho e as culturas passam pela reestruturação ou como são transformados por ela, e como a remuneração pode ser eficazmente relacionada a estes processos de mudanças. Para tornar este processo de transformação uma jornada mais fácil, as organizações devem adotar uma abordagem de negociação para grande mudança organizacional. Trata-se de um processo contínuo que abrange o processo de mudança desde a reformulação da cultura de trabalho até a criação de novas estratégias de remuneração para a organização com o um todo (Flannery, 1997).

\section{Metodologia}

Este artigo é baseado em pesquisa exploratória que buscou verificar como a remuneração influencia no processo de mudança organizacional. Segundo Barros \& Lehfeld (2000), a tipologia de pesquisa utilizada neste estudo foi a pesquisa teórica e prática, que englobou a revisão bibliográfica e a pesquisa de campo. Na revisão bibliográfica foi realizado um levantamento dos temas e tipos de abordagens já trabalhados por outros estudiosos, assimilando conceitos e explorando aspectos já publicados. A pesquisa de campo foi utilizada para coletar dados em empresas sediadas no Brasil.

Para realizar a coleta de dados da pesquisa de campo foram aplicados questionários como instrumento para o levantamento de informações nas empresas. Estes foram entregues e respondidos por escrito pelos responsáveis dos Departamentos de Recursos Humanos através de perguntas abertas. A aplicação e devolução dos questionários se deram através de correio eletrônico, após o contato por telefone. O critério utilizado para escolha das empresas foi o fato destas estarem dentro do ranking da Revista Exame, como as 100 melhores empresas para se trabalhar. $\mathrm{Na}$ fase de coleta de dados foram reunidas informações sobre dados financeiros, históricos, estruturais e culturais, e dados relacionados aos recursos humanos de 4 empresas que se dispuseram a oferecer as informações solicitadas e a responder o questionário no tempo estipulado.

A partir dos dados coletados foi realizada uma análise de conteúdo de acordo com as preposições de Bardin (1977). A partir desta análise foram elaborados os estudos de casos de cada empresa que deram margens às conclusões deste estudo. Visto que segundo Yin (1994), o estudo de caso é adequado para análises mais aprofundadas de um determinado fenômeno.

\section{As Mudanças na Metodologia de Remuneração e o Impacto nas Empresas}

A seguir tem-se os estudos de caso formulados a partir da análise de conteúdo dos questionários e dos relatórios informativos fornecidos pelas empresas CETREL S/A 


\section{Revista Eletrônica de Ciência Administrativa (RECADM) - ISSN 1677-7387 \\ Faculdade Cenecista de Campo Largo - Coordenação do Curso de Administração v. 3, n. 1, maio/2004 - http://revistas.facecla.com.br/index.php/recadm/}

Empresa de Proteção Ambiental, Computer Associates, Lojas Renner S/A e WEG Indústrias S/A.

\subsection{CETREL S/A - Empresa de Proteção Ambiental}

A remuneração básica dos recursos humanos praticada atualmente pela Cetrel é a Metodologia de Remuneração por Habilidades e Competências. Segundo a líder de Recursos Humanos da empresa, "O processo de definição do salário dos nossos funcionários é feito através de uma avaliação das habilidades e competências que cada um deles possui, utilizando-se para tanto um Comitê Avaliador, e de acordo a pontuação obtida pelo empregado é feita à definição do seu salário”.

Além da Remuneração por Habilidades e Competências, a Cetrel pratica ainda uma outra metodologia de Remuneração Variável, o Programa de Participação nos Resultados. Antes de adotar a metodologia que pratica hoje, a empresa adotava a Promoção por Mérito, que era uma forma de remuneração funcional, baseada no cargo. Conforme indicou a pessoa contatada na empresa, "mudamos para habilidades e competências porque os empregados não estavam satisfeitos e sentiam-se injustiçados com a metodologia anterior”.

A Cetrel acredita que a metodologia de remuneração dos recursos humanos é capaz de influenciar os resultados empresariais. A justificativa da empresa para esta afirmativa, é que quando se possui uma metodologia que valoriza o empregado, pode-se fazer distinção dentro de seu segmento. A empresa acredita ainda que a Remuneração Variável pautada em metas é capaz de trazer desafios, o que atrai a atenção dos funcionários, já que o ser humano gosta de ser constantemente desafiado. A Cetrel espera que sua Política de Administração Salarial seja capaz de valorizar os seus recursos humanos, ser atrativa para entrada de novos empregados e reter os talentos que já possui.

Analisando os últimos cinco anos, a Cetrel percebeu uma melhora em termos motivacionais em uma série de indicadores, como o aumento de produtividade e qualidade, devido a sua atual política de Administração Salarial. A melhoria trazida pela atual política de Administração Salarial é bem evidente na Cetrel, conforme pode ser observado neste depoimento "O Programa de Participação de Resultados é baseado em ganhos de produtividade e tem conseguido melhorar uma série de indicadores. A Remuneração por Habilidades e Competências é vista pelo empregado como um modelo justo e isto o motiva para o trabalho e para a busca de seu desenvolvimento profissional.”

\subsection{Computer Associates}

A metodologia de remuneração básica dos recursos humanos praticada pela Computer Associates é remuneração funcional. Conforme indica a gerente de recursos humanos para América Latina, "Trata-se de uma metodologia de remuneração funcional, onde o salário é definido através da pesquisa de mercado e definição de faixas salariais para cada cargo. A pesquisa salarial de mercado é realizada anualmente e o valor também sofre alterações de acordo com o dissídio coletivo de cada uma das categorias”.

Recentemente, a empresa também passou a adotar a remuneração variável, utilizando a metodologia de participação nos lucros e resultados, através do qual a empresa vem distribuindo aos seus funcionários dezenas de milhões de dólares a cada ano.

Segundo a entrevistada, a Computer Associates acredita que a metodologia de remuneração dos recursos humanos é capaz de influenciar os resultados empresariais, pois "a prática de remuneração de uma empresa direciona seus profissionais ao atingimento de objetivos que estejam alinhados com os objetivos de cada departamento e este, alinhado com os objetivos gerais da empresa”. 


\section{Revista Eletrônica de Ciência Administrativa (RECADM) - ISSN 1677-7387 \\ Faculdade Cenecista de Campo Largo - Coordenação do Curso de Administração v. 3, n. 1, maio/2004 - http://revistas.facecla.com.br/index.php/recadm/}

A empresa passou por uma grande mudança organizacional sob vários aspectos, estas mudanças ocorreram na cultura organizacional, na imagem institucional, e na estrutura organizacional, com a modificação da estratégia de gestão e ação da empresa. Devido às peculiaridades de seu segmento, a empresa é obrigada a realizar mudanças constantemente, visto que o mercado de tecnologia exige flexibilidade e adaptabilidade. Estas mudanças foram bem aceitas pela organização, e principalmente pelos recursos humanos, pois a administração salarial facilitou sua implementação, agindo como ponto de apoio no reforço de comportamentos de desempenho esperados pela organização.

A Computer Associates acredita que sua política de administração salarial é capaz de mantê-la atualizada em relação ao mercado em que atua. Pois, através da análise dos últimos cinco anos, a empresa foi capaz de perceber uma melhora nos resultados financeiros e de produtividade, registrando no ano de 2001, um volume de negócio de 4.198 milhões de dólares e um aumento de $12 \%$ de ganho por ação.

\subsection{Lojas Renner S/A - Comércio varejista}

A atual metodologia de remuneração básica dos recursos humanos praticada pelas Lojas Renner é a Remuneração por Competências, onde o processo de definição do salário dos seus funcionários é feito a partir da avaliação de desempenho de 360 graus, ou seja, uma avaliação onde participam todas as pessoas em torno do avaliado, cujos resultado define o número de pontos de cada funcionário para o enquadramento numa tabela salarial previamente definida pela empresa. Esta tabela possui intervalos salariais de aproximadamente $20 \%$ entre os pontos.

A Renner pratica ainda a metodologia de remuneração variável, conforme indicou o gerente de relações trabalhistas e remuneração da empresa, Sr. Amarildo de Souza. Segundo ele, "Praticamos a remuneração variável para área de vendas, onde os vendedores são remunerados com um percentual de acordo com a venda da loja”.

A empresa já utilizou anteriormente uma outra metodologia de remuneração de seus recursos humanos, a remuneração funcional através do sistema de pontos, que era reajustado somente em caso de promoções ou por mérito. A alteração ocorreu em Janeiro de 2000, quando foi implantado o sistema de avaliação de desempenho em 360 graus, a mudança foi resultado de uma decisão do departamento de recursos humanos da empresa.

A Renner acredita que a metodologia de remuneração dos recursos humanos é capaz de influenciar os resultados empresariais, pois a metodologia de remuneração deve estar vinculada com a avaliação de desempenho, para que sejam estabelecidos critérios justos, o que é fundamental para estimular o desenvolvimento das pessoas para permitir que eles alcancem os resultados esperados.

A empresa vem passando por uma mudança organizacional desde que foi adquirida pela empresa J.C. Penney, houve uma reestruturação comercial, que substituiu o modelo de loja de departamentos full line pelo conceito de loja com especialização em moda. A mudança foi bem aceita pela organização e não houve choque entre a gerência e os funcionários. A administração salarial facilitou a implementação destas mudanças, pois estabeleceu uma nova política de remuneração no momento crucial para o processo de mudança. Conforme relatou o Gerente de Relações Trabalhistas e Remuneração, a Renner espera que sua política de administração salarial "seja o mais simples e justa possível, para que possa ser entendida e aprovada por todos os nossos funcionários”.

Analisando os últimos cinco anos, as Lojas Renner perceberam que houve melhora nos resultados de produtividade devido a sua atual política de administração salarial. Neste mesmo período, a empresa aumentou sua receita em seis vezes e atingiu níveis de lucratividade que excederam muitas companhias internacionais, registrando um 


\section{Revista Eletrônica de Ciência Administrativa (RECADM) - ISSN 1677-7387 \\ Faculdade Cenecista de Campo Largo - Coordenação do Curso de Administração v. 3, n. 1, maio/2004 - http://revistas.facecla.com.br/index.php/recadm/}

crescimento de 558\% no faturamento. Esta empresa vem registrando uma performance fora do comum no varejo brasileiro. Os seus indicadores econômicos descrevem uma curva continuamente ascendente nos últimos anos.

\subsection{WEG Indústrias S/A - Empresa metalúrgica}

A atual metodologia de remuneração dos recursos humanos praticada pela empresa WEG é a Remuneração por Pontos para os cargos de nível operacional, nível técnico e de supervisão. A Remuneração funcional é a forma de remuneração básica praticada pela empresa. Porém, há aproximadamente dois anos a WEG também passou a praticar uma metodologia de remuneração variável, a Participação nos Lucros e Resultados (PLR), pago semestralmente com base em critérios estabelecidos.

O valor total da parcela paga pela WEG a seus colaboradores referente à distribuição de lucros do segundo semestre de 2001, foi de aproximadamente $\mathrm{R} \$$ 25.115.000,00. Os funcionários que atingiram todas as metas do PWQP - Programa Weg de Qualidade e Produtividade, receberam quase 2 salários a mais referentes à participação nos lucros, que juntando com a antecipação paga em agosto de 2001, que foi de 1,3 salários, ultrapassa a marca de 3 salários em um ano. Ou seja, o funcionário da WEG que atingiu todas as suas metas, teve além do $13^{\circ}$, o $14^{\circ}$, o $15^{\circ}$ e o $16^{\circ}$ salários.

Com relação ao processo de definição do salário dos funcionários da WEG, a Analista de Marketing Interno da empresa, indicou que "o salário é definido através da estrutura de cargos existente e acompanhamento através de pesquisas salariais".

Esta empresa também acredita que a metodologia de remuneração dos recursos humanos é capaz de influenciar os resultados empresariais, embora não seja considerada atualmente, como o único fator que influencia nos resultados obtidos. Porém, é um das responsáveis pelo sucesso que a empresa vem obtendo em seu segmento. Aliado a remuneração, a WEG cuida de fatores como ambiente de trabalho, clima interno, administração participativa e outros. Conforme relatado pela Analista de Marketing Interno, a WEG acredita que sua administração salarial é capaz de "estruturar uma política compatível com o mercado a fim de atrair e reter talentos, além de tê-los motivados e engajados com os objetivos da organização. As pessoas são nossos principais ativos, ou ainda, nossos colaboradores são a fonte de nossa vantagem competitiva”.

Segundo a entrevistada, ao se analisar os últimos cinco anos a empresa percebe-se uma melhora devido à política de Administração Salarial que tem praticado na empresa. "Percebemos um aumento da satisfação e motivação dos funcionários, que é medido através de pesquisas de clima organizacional que são realizadas na empresa, bem como através do interesse das pessoas que ainda não fazem parte de nosso quadro de colaboradores em trabalhar na WEG”.

Com relação aos resultados financeiros obtidos, a empresa WEG também apresentou um bom desempenho nas vendas, ultrapassando a barreira de 1 Bilhão de Reais. Seu Balanço 2001 mostra que o faturamento consolidado do grupo atingiu o montante de R\$ 1.268,9 Bilhões, apresentando um crescimento de 32\% em relação ao ano anterior. As exportações foram responsáveis por 35\% da receita operacional líquida, com o faturamento de US\$ 175,6 Milhões no mercado externo. Para 2002, a WEG projeta um faturamento de R\$ 1.526 Bilhão e um crescimento de $21 \%$ em relação ao ano anterior.

\section{Considerações Finais}

Analisando as empresas pesquisadas percebe-se que a remuneração básica praticada pelas empresas vem mudando com o decorrer do tempo; antes a remuneração funcional era 
Revista Eletrônica de Ciência Administrativa (RECADM) - ISSN 1677-7387

Faculdade Cenecista de Campo Largo - Coordenação do Curso de Administração v. 3, n. 1, maio/2004 - http://revistas.facecla.com.br/index.php/recadm/

a preferida das empresas, hoje já divide espaço com a remuneração por habilidades ou por competências. Das empresas pesquisadas, duas utilizam a remuneração funcional combinada à metodologia de participação nos lucros e resultados, uma utiliza a remuneração por competências e outra a remuneração por habilidades e competências. Anteriormente todas as empresas pesquisadas utilizavam a remuneração funcional como base de remuneração.

A remuneração variável é bastante utilizada como complemento ao salário base. Das empresas pesquisadas, duas optaram pela participação nos lucros e resultados para todos os cargos, uma adotou a participação nos resultados para todos os cargos e a outra adotou a participação nos resultados somente para o departamento comercial.

A partir dos resultados apresentados consegue-se chegar as seguintes conclusões:

- A metodologia de remuneração por habilidades e/ou competências apresentou como resultado o aumento da motivação e do incentivo ao desenvolvimento profissional;

- A metodologia de remuneração funcional apresentou como resultado, em algumas situações, acomodação e sentimento de injustiça por parte dos funcionários, em outras, apresentou bons resultados, devendo, portanto, ser administrada com cautela;

- A metodologia de remuneração por participação nos lucros e/ou resultados apresentou um aumento da produtividade, da qualidade e da lucratividade empresarial.

Através das empresas pesquisadas percebe-se que a metodologia de remuneração adotada influenciou no processo de mudança organizacional a que estas se submeteram.

A eficiente utilização das metodologias de remuneração nestas empresas influenciou positivamente os resultados apresentados e serviu de apoio para a implementação da mudança organizacional. Com base nos resultados obtidos e nas conclusões, sugere-se a realização de novos estudos para a confirmação destes resultados em empresas de outros setores e/ou até mesmo para a comprovação de que uma metodologia de remuneração ineficiente é capaz de influenciar negativamente os resultados empresariais e impedir a implementação de processos de mudança organizacional.

\section{Referências Bibliográficas}

BARDIN, L. (1977). Análise de conteúdo. Lisboa: Edições 70.

BARROS, A.J.S. \& LEHFELD, N.A.S. (2000). Fundamentos de metodologia científica. 2.ed. São Paulo: Makron Books.

BATISTA, Luciene Gouveia. (2002). Remuneração: uma análise comparativa das metodologias adotadas pelas empresas no Brasil e sua influência na mudança organizacional. Seropédica: UFRRJ, 2002. 72p. (Dissertação, Mestrado Profissional em Gestão e Estratégia em Negócios).

CHAGURI, R. (2000). Manual prático da remuneração moderna. São Paulo: LTR.

CHIAVENATO, I. (1999). Gestão de pessoas: o novo papel dos recursos humanos nas organizações. Rio de Janeiro: Campus.

CHIAVENATO, I. (1998). Remuneração, benefícios e relações de trabalho. 2ed. São Paulo: Atlas.

DESSLER, G. (1997). Human resource management. Upper Sadlle River, NJ, Prentice Hall.

FLANNERY, T P. (1997). Pessoas, desempenho e salários: as mudanças na forma de remuneração nas empresas. Tradução: Bazán Tecnologia e Lingüística. São Paulo: Futura.

MAXIMIANO, A.C.A. (2000). Teoria geral da Administração. 2 ed. São Paulo: Atlas. 
Revista Eletrônica de Ciência Administrativa (RECADM) - ISSN 1677-7387

Faculdade Cenecista de Campo Largo - Coordenação do Curso de Administração v. 3, n. 1, maio/2004 - http://revistas.facecla.com.br/index.php/recadm/

NASCIMENTO, L P. (2001). Administração de cargos e salários. São Paulo: Pioneira Thomson Learning.

PICARELLI FILHO, V. \& Equipe Coopers \& Lybrand. (1997). Remuneração por habilidades e por competências: preparando a organização para a era das empresas do conhecimento intensivo. São Paulo: Atlas.

PRAHALAD, C.K. \& HAMEL , G. (1995). Competindo para o futuro. Rio de janeiro: Campus.

WOOD JR, T. \& PICARELLI FILHO, V. (1999). Remuneração estratégica: a nova vantagem competitiva. São Paulo: Atlas.

YIN, R. (1994). Case study research: design and methods. Applied Social Research Methods Series; V.5. London: Sage. 